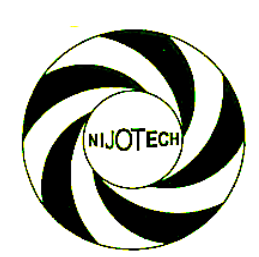

Nigerian Journal of Technology (NIJOTECH)

Vol. 37, No. 2, April 2018, pp. 514-518

Copyright@ Faculty of Engineering, University of Nigeria, Nsukka,

Print ISSN: 0331-8443, Electronic ISSN: 2467-8821

www.nijotech.com

http://dx.doi.org/10.4314/njt.v37i2.30

\title{
DEMONSTRATIVE EFFECT OF ADAPTED HYDRAULIC RAM AS A DRAWBAR DYNAMOMETER IN TRACTOR OPERATIONS
}

\author{
A. O. Ezeama ${ }^{1,{ }^{*}, \text { P. I. Obe }}{ }^{2}$ and O. M. Egbuhuzor ${ }^{3}$

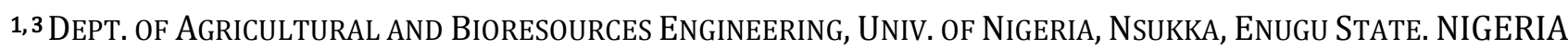 \\ 2, DEPARTMENT OF INDUSTRIAL TECHNiCAL EdUCATION, UNIVERSITY OF NiGERIA, NSUKKA, ENUGU STATE. NiGERIA \\ E-mail addresses: ${ }^{1}$ osita.ezeama@unn.edu.ng, ${ }^{2}$ pauline.obe@unn.edu.ng, \\ 3 onyekachi.egbuhuzor@unn.edu.ng
}

\begin{abstract}
This study is focused on adapting a pair-loader hydraulic ram for use as a drawbar hydraulic dynamometer for field tests and presenting simulative views in 3D. The ram pressure unit consists of a cylinder, piston and push rod with the hydraulic cylinder having a capacity of $26.7 \mathrm{kN}$ draft was used. The maximum length of ram is $540 \mathrm{~mm}$, diameter of piston is $80 \mathrm{~mm}$, and diameter of cylinder is $120 \mathrm{~mm}$. A hand held pressure gauge was used with maximum range capacity of $11 \mathrm{~N} / \mathrm{mm}^{2}$. The transmission line was made of a high pressure oil rubber hose, $2.75 \mathrm{~m}$ long, and hydraulic adaptors were used to connect the oil tube to the cylinder and the pressure measuring gauge. Hydraulic dynamometers using calibrated pressure gauge indicator was adapted to measure heavy draft loads. It can be used to determine the draft, drawbar pull and travel reduction (slip) of a tractor with implement in operation and when not in operation. $A$ field test carried out showed that at any given drawbar pull, the slippage increased with increase in draft (drawbar pull).
\end{abstract}

Keywords: Hydraulic dynamometer, drawbar power, tillage operation, field demonstrative tests

\section{INTRODUCTION}

There are many criteria that have been used to evaluate various tillage methods. The major areas include the effects of different tillage methods on physical and mechanical properties of the soil, crop emergence, growth and yield, relative costs and benefits [1]. Tillage operation is one of the crop production operations requiring high energy input; a considerable amount of work and effort should be directed towards a practical evaluation of tillage operation with respect to its energy requirement. This is necessary in order to get the best fit between implements and power units in terms of energy efficiency. Output from power sources are measured using dynamometers. Dynamometer ranges from the hydraulic type, spring, strain gauge and absorption types to the transmission type. An attempt at constructing a hydraulic drawbar dynamometer was made by Onyezuluigbo [3] and was modified by Uke [4]. It is important to develop an instrument that will help in defining the tillage operations dimensions/data which are measurable, keeping to standards and reducing risks during field operation tests. Due to different ecological zones in Nigeria, the importance of the study will be better appreciated when looked at from the national point of view, because each zone has different soil characteristics. During field operation, field operating data for tillage machineries need to be compiled for different soil types and conditions. These information can be used to determine the range of power requirement of such implements under various soil conditions. This makes it possible for proper matching of the implement to the appropriate power unit. The implement-tractor matching is very important because it makes for appropriate; work thereby making the job economical by using the tractor of appropriate power. The matching of a power unit to an implement requires knowledge of the power requirement of the implement and depends not only on the engine power but on employing suitable tractive devices and ballasting to ensure that the power is available at the drawbar while minimizing waste. Proper matching of implements become difficult due to lack of information on the performance of tractor-implement combinations leading to consumption of excessive energy and consequent high costs $[2,5,6]$. To measure these

* Corresponding author, tel: +234-803- $779-3934$ 
powers, various forms of force measuring transducers like the dynamometer are used as drawbar performance is measured at different rates of pulls and gears. The main objectives of this study are to adapt a pair-loader hydraulic ram for use as a hydraulic drawbar dynamometer and to carry out a performance evaluation of the adapted pair-loader hydraulic ram.

\section{DESIGN CONSIDERATIONS}

The adapted pair-loader hydraulic ram for use as a drawbar dynamometer consists of three main parts, namely: the hydraulic or pressure unit; the pressure measuring gauge or registering device and the transmission line or connecting hose. The pressure unit consists of a cylinder, piston and push rod with the hydraulic cylinder having a capacity of $26.7 \mathrm{kN}$ draft. The maximum length of ram is $540 \mathrm{~mm}$, diameter of piston is $80 \mathrm{~mm}$, and diameter of cylinder is $120 \mathrm{~mm}$. A hand held pressure gauge was used with maximum range capacity of $11 \mathrm{~N} / \mathrm{mm}^{2}$. The transmission line was made of a high pressure oil rubber hose, $2.75 \mathrm{~m}$ long, and hydraulic adaptors were used to connect the oil tube to the cylinder and the pressure measuring gauge. The assembly drawing of the fairly used Pair-Loader ram and the brackets are shown in Figure 1.

\subsection{Design Calculations}

The force that actuates the fluid in the hydraulic ram is given by:

$$
F=m a=P A L \times \frac{d v}{d t}
$$

The pressure from outlet point to the pressure gauge is obtained by dividing the force $\mathrm{F}$ in equation (1) by the area $\mathrm{A}$ :

$$
P_{3}=F / A
$$

The power required can be calculated using the expression:

$$
P=p g Q h
$$

The efficiency of the drawbar Hydraulic Dynamometer is given by:

$$
E=\frac{Q \times h}{(Q+Q W) \times H}
$$

\subsection{Determination of Design Parameters for the Drawbar Hydraulic Dynamometer (DHD)}

- Universal Testing Machine (UTM) as accurate torque testing equipment was used on the DHD

- Support structure design was optimized for coupling stiffness/deflection) analysis to test. The strength of the materials DHD

The coupling stiffness constant of solid bar and rod is expressed by equation 5 .

$$
K=\frac{F}{\delta}=\frac{A E}{L}
$$

Where $\mathrm{K}$ is the coupling stiffness constant, $\mathrm{N} / \mathrm{m}, \mathrm{F}$ is the force on the body, $\mathrm{N} ; \delta=F L / A e$ is the displacement produced by the force along same degree of freedom, $\mathrm{m}, \mathrm{A}$ is the cross sectional Area, $\mathrm{m}^{2}, \mathrm{E}$ is the Modulus of elasticity, $\mathrm{N} / \mathrm{m}^{2}$, $\mathrm{L}$ is the Length, $\mathrm{m}$

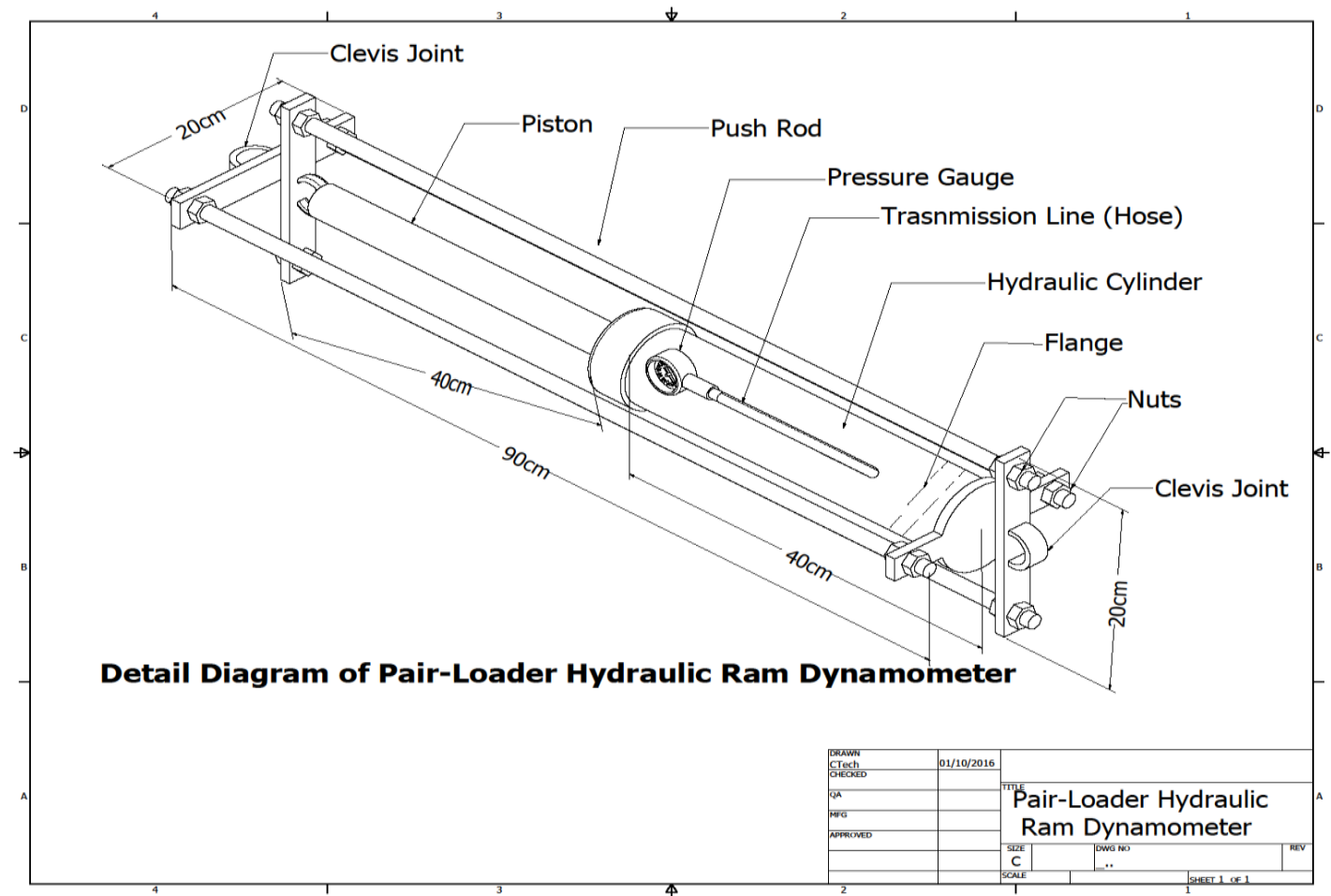

Figure 1: The assembly drawing of the pair-loader hydraulic ram for use as a drawbar hydraulic dynamometer. 


\subsection{Determination of load application to actuate DHD}

The hydraulic ram cylinder and piston reciprocally disposed in the barrel due to load (Preload or initial tensile load, $\mathrm{F}_{\mathrm{i}}$ in the UTM), at mounting point on UTM, the external load, $\mathrm{F}_{\mathrm{e}}$ is applied resulting to increase in length of rod equal to $\mathrm{F}_{\mathrm{eb}} / \mathrm{K}_{\mathrm{b}}$ and decrease in deformation of DHD equal to $\mathrm{F}_{\mathrm{ep}} / \mathrm{K}_{\mathrm{p}}$. If the changes in deformation are equal, we have:

$$
\begin{gathered}
\frac{F_{e b}}{K_{b}}=\frac{F_{e p}}{K_{p}} \\
F_{e}=F_{e b}+F_{e p} \\
F_{e b}=F_{e p} \frac{K_{b}}{K_{p}}=\frac{K_{b}}{K_{p}}\left(F_{e}-F_{e b}\right)=\frac{K_{b}}{K_{b}+K_{p}} F_{e}
\end{gathered}
$$

And similarly

$$
F_{e b}=\frac{K_{b}}{K_{b}+K_{p}} F_{e}
$$

The total force on the rod is then

$$
F_{b}=F_{e b}+F_{i}=\frac{K_{b} F_{e}}{K_{b}+K_{p}}-F_{i}
$$

And the total compressive load on the DHD is:

$$
F_{p}=F_{e p}+F_{i}=\frac{K_{p}}{K_{p}+K_{P}} F_{e}-F_{i}
$$

\section{INSTRUMENT CALIBRATION}

The selected pair-loader hydraulic ram was tested using a hydraulic crane of capacity $44.5 \mathrm{kN}$ at Science Equipment and Development Institute (SEDI), Akwuke, Enugu. The test was to check for leakages and to achieve a closed hydraulic system. The hydraulic ram was calibrated for accuracy with the use of a "universal

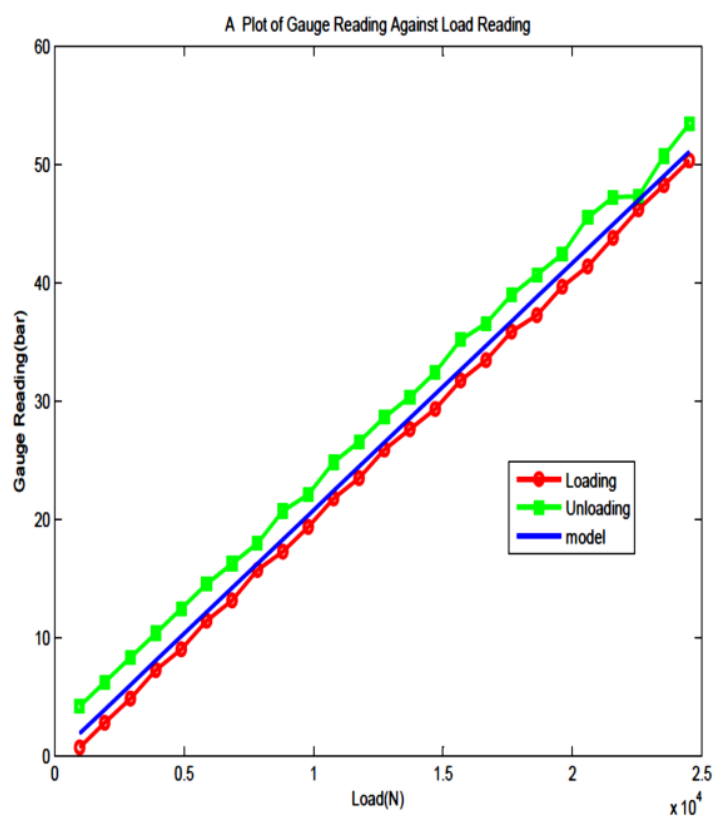

Figure 2: A plot of gauge reading against load reading testing machine" (UTM). Direct loading by use of known force at an incremental rate of $1000 \mathrm{~N}$ per time was used in the calibration. The resulting gauge readings were noted. The unloading readings / using the same rate as for loading were also taken and corresponding pressure gauge reading and the length of the piston were also noted. The ratio of load to gauge reading was constant and the calibration curve is a straight line. The calibration test indicated a high factor of safety for the unit which was designed to withstand $26,700 \mathrm{~N}$ while the maximum applied load was $24,525 \mathrm{~N}$. The adopted pair loader hydraulic ram drawbar dynamometer calibration readings during loading and unloading are shown in Figures 2 and 3 respectively.

The non-coincidence of the loading and unloading curves is due to: (a) the friction existing between the cylinder and piston (b) the internal friction or hysteretic damping of the stressed parts.

\section{RESULTS AND DISCUSSION}

The test was carried out in a grass covered land at the demonstration field of the department of Agriculture and Bioresources Engineering, University of Nigeria, Nsukka. The tractor used to test the adopted pair loader ram used for the hydraulic dynamometer drawbar was pulled by another tractor that was connected to it by a chain and the hydraulic drawbar dynamometer.

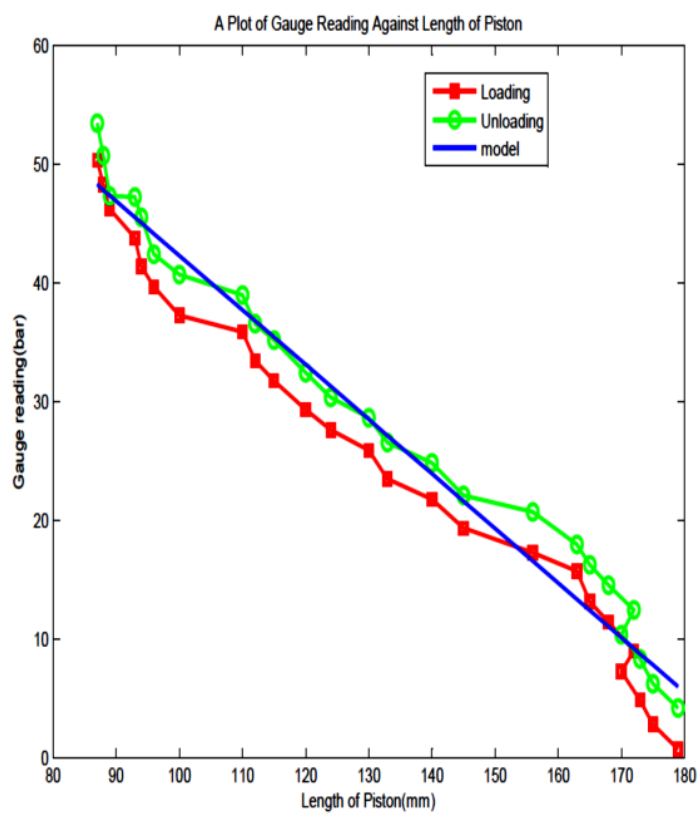

Figure 3: A plot of gauge reading against length of piston 
The tractor used for the test was made to apply increasing drawbar loads by selection of the lowest gear of high speed (HI gear ratio). It was ran under constant engine speed of 1800r.p.m. Load changing for the gear selection was adopted to correspond with values of load from the calibration reading during loading. In order to determine maximum possible draft, corresponding values of the dynamometer pressure gauge readings were recorded as the tractor hitched with the dynamometer was pulled.

\subsection{Performance Test Result}

A field test on the adapted pair-loader hydraulic ram was carried out to determine its suitability for use as a hydraulic dynamometer for field test. Table 1 and 2 present the results from the field test. In fig. 4, the load and slip (travel reduction) show that slip increases with increase in draft when the implement is both in operation and out of operation. Also, fig. 5, the graph of gauge reading and slip show the same character as that of load and slip in the two conditions (implement in operation and out of operation). This goes to show that draft (drawbar pull) resulting to the dynamometer gauge reading are similar. Tire slip variability is dependent upon the load and other soil parameters. Thus increase in load shows an increase in slip but higher when implement is in operation as shown in graph of Figure 5. Figure 6 shows the dynamometer in field test.

\section{CONCLUSION}

The adapted pair-loader hydraulic ram for use as a drawbar hydraulic dynamometer in the field tests was achieved. This was confirmed by the calibration and the field performance test data. The instrument will help in field test aimed at evaluation of some of the farm implements and machineries. In field test, it was observed that increase in slippage obviously reduces the service life of the tires productivity. Thus, slip is the result of correct drive wheel ballast since slip is controlled by adding or removing ballast from the tractor to obtain the desired slip as also determined by Raheman and Jha in [7].

Table 1: Performance test with tractor having implement not in operation

\begin{tabular}{cccccccc}
\hline Runs & $\begin{array}{c}\text { Load } \\
(\mathrm{N})\end{array}$ & $\begin{array}{c}\text { Gauge reading } \\
(\text { Bar })\end{array}$ & $\begin{array}{c}\text { No of } \\
\text { Rev. }\end{array}$ & $\begin{array}{c}\text { Distance covered } \\
(\mathrm{m})\end{array}$ & $\begin{array}{c}\text { Distance per } \\
\text { Rev.(m/rev. })\end{array}$ & $\begin{array}{c}\text { (\%) } \\
\text { slip }\end{array}$ & $\begin{array}{c}\text { Time taken } \\
(\mathrm{sec}) .\end{array}$ \\
\hline 1 & 0 & 0 & 10 & 43.49 & 4.34 & 0 & 30 \\
2 & 4000 & 8.618 & 10 & 41.61 & 4.16 & 4.15 & 31 \\
3 & 4300 & 9.515 & 10 & 41.12 & 4.12 & 5.07 & 31 \\
4 & 4900 & 9.791 & 10 & 40.80 & 4.08 & 5.99 & 32 \\
5 & 5600 & 12.07 & 10 & 39.34 & 3.93 & 9.45 & 33 \\
6 & 6400 & 13.79 & 10 & 37.73 & 3.77 & 13.13 & 33 \\
7 & 7800 & 15.17 & 10 & 36.90 & 3.36 & 15.44 & 34 \\
8 & 8100 & 17.24 & 10 & 35.90 & 3.60 & 17.05 & 36 \\
9 & 9000 & 18.96 & 10 & 34.45 & 3.45 & 20.51 & 37 \\
10 & 11000 & 23.58 & 4 & 16 & 1.6 & 63.13 & 12 \\
\hline
\end{tabular}

Table 2: Performance test with tractor having implement in operation

\begin{tabular}{cccccccc}
\hline Runs & $\begin{array}{c}\text { Load } \\
(\mathrm{N})\end{array}$ & $\begin{array}{c}\text { Gauge reading } \\
\text { (Bar) }\end{array}$ & $\begin{array}{c}\text { No of } \\
\text { Rev. }\end{array}$ & $\begin{array}{c}\text { Distance covered } \\
(\mathrm{m})\end{array}$ & $\begin{array}{c}\text { Distance per } \\
(\text { Rev. })\end{array}$ & $\begin{array}{c}\text { (\%) } \\
\text { slip }\end{array}$ & $\begin{array}{c}\text { Time taken } \\
(\mathrm{sec})\end{array}$ \\
\hline 1 & 0 & 0 & 10 & 42.51 & 4.25 & 0 & 31 \\
2 & 2200 & 5.171 & 10 & 41.84 & 4.18 & 1.65 & 34 \\
3 & 3100 & 6.895 & 10 & 41.52 & 4.15 & 2.35 & 36 \\
4 & 3700 & 7.584 & 10 & 41.22 & 4.12 & 3.06 & 39 \\
5 & 5600 & 12.07 & 10 & 40.14 & 4.01 & 5.65 & 43 \\
6 & 8100 & 17.24 & 10 & 37.23 & 3.72 & 12.47 & 48 \\
7 & 9500 & 18.62 & 10 & 36.25 & 3.62 & 14.59 & 49 \\
8 & 11300 & 24.13 & 10 & 32.42 & 3.24 & 23.76 & 58 \\
9 & 13000 & 27.58 & 10 & 26.14 & 2.61 & 38.59 & 64 \\
10 & 14700 & 31.03 & 8 & 30.20 & 3.02 & 28.94 & 27 \\
\hline
\end{tabular}




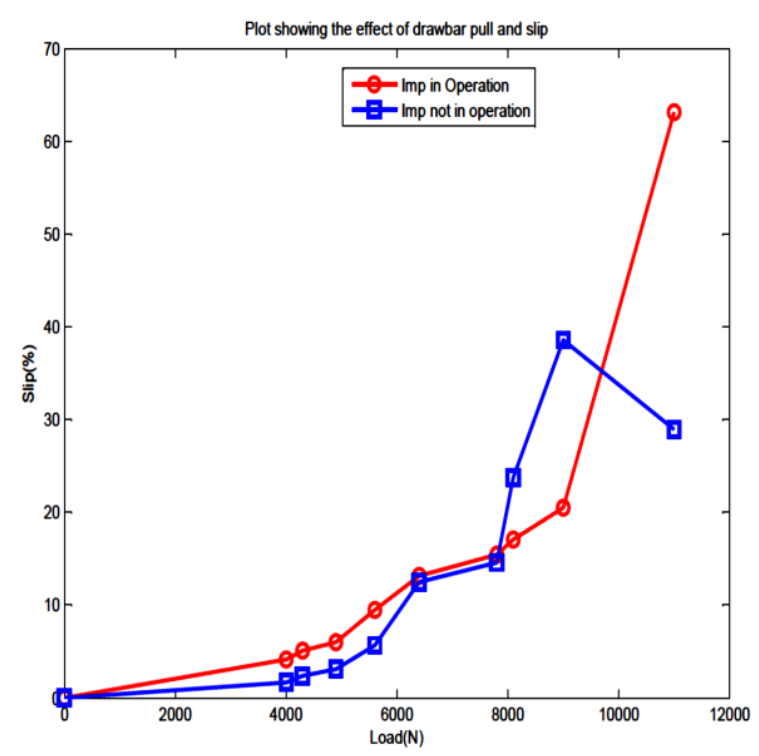

Figure 4: Plot showing the effect of slip and load

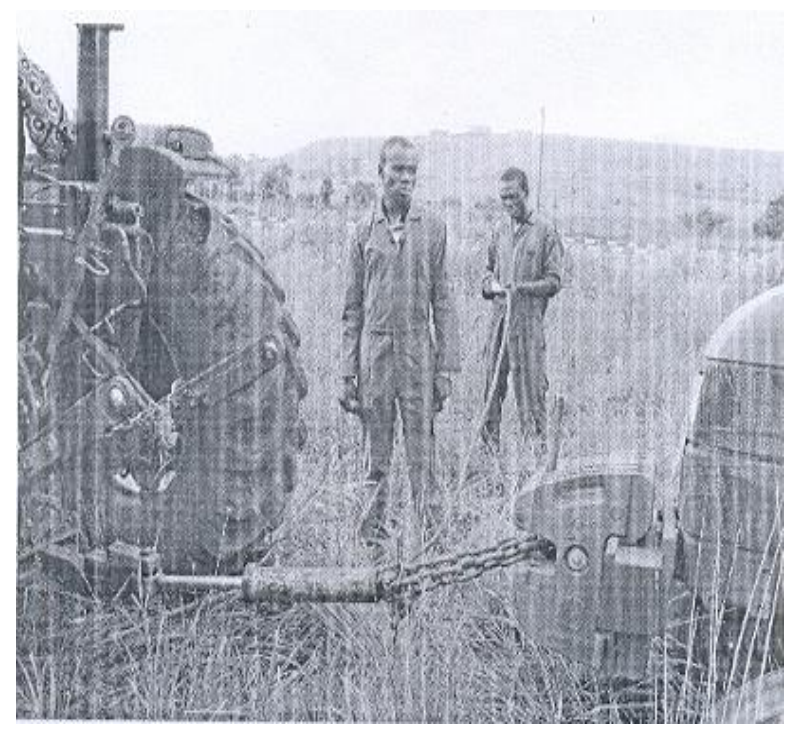

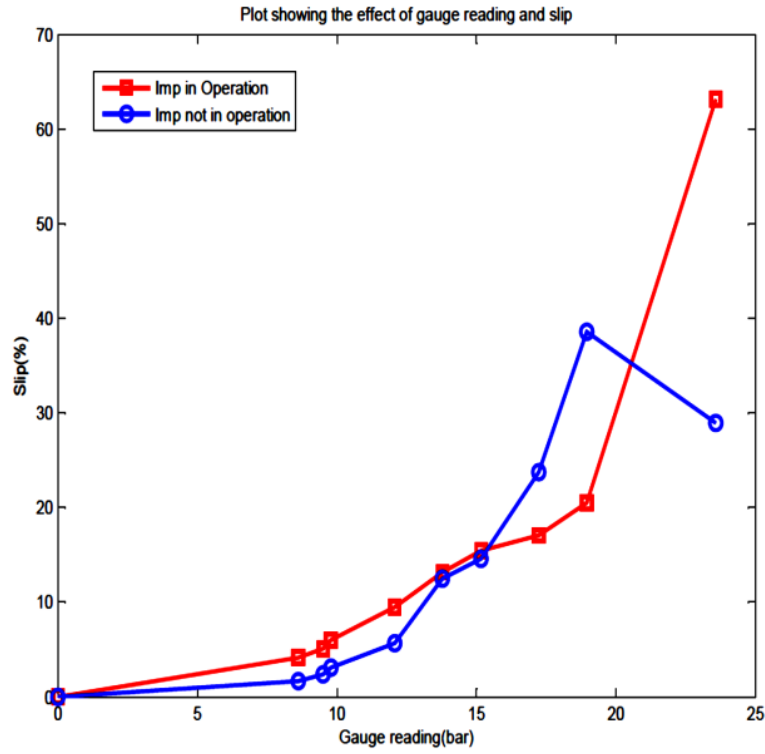

Figure 5: Plot showing the effect of slip and gauge

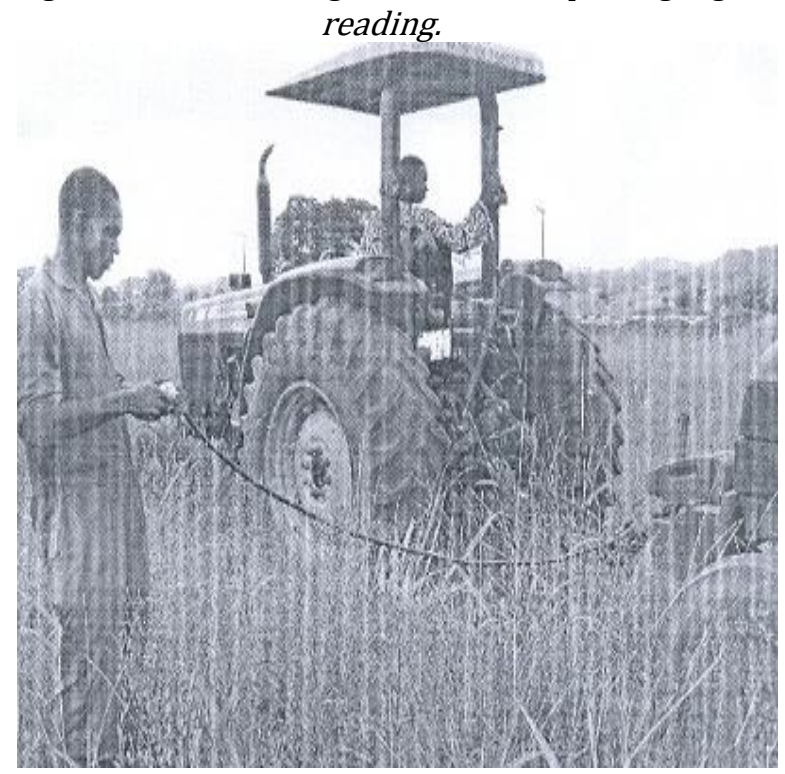

Figure 6: Dynamometer hitched at the drawbar

\section{REFERENCES}

[1] Anazodo, U.G.N., A.P. Onwualu and M.N. Uke,. Draught and energy requirements in ploughing after five years of conventional and reduced tillage, Proc. of the NSAE, Vol. 11, pp 108-120, 1987.

[2] Edathiparambil, V.T. and B. Singh. Performance of Tractor Implement combination. Agricultural Mechanization in Asia, Africa and Latin America. Vol. 33 No 2. pp 25-30, 2002.

[3] Onyezuligbo, C.O.. Design, Construction and testing of a Hydraulic Drawbar Dynamometer. B. Eng. Thesis, Department of Agricultural Engineering, University of Nigeria, Nsukka., 1975.

[4] Uke, M.N..Modification, calibration and use of the Hydraulic Drawbar Dynamometer. B. Eng. Thesis,
Department of Agricultural Engineering, University of Nigeria, Nsukka, 1987.

[5] Chen, Y., N.B. McLaughlin and S. Tessier. Double extended octagonal ring (DEOR) drawbar dynamometer. Soil and Tillage Research, Volume 93, Issue 2, pp462-471., 2007

[6] Sahu, R.K. and H. Raheman. A decision support system on matching and field performance prediction of tractor-implement system. Computers and Electronics in Agriculture, Volume 60, Issue 1, pp76-86, 2008.

[7] Raheman, H .and S.K. Jha, . Wheel slip measurement in 2WD tractor. Journal of Terramechanics, Volume 44, Issue1, pp.89-94. 2007 